\title{
Book Review: Handbook of Conversation Design for Instructional Applications
}

\author{
Murat Ataizi \\ Anadolu University, Turkey
}

This Handbook (ISBN: 978-1-59904-597-9) is published by IGI Global, Hersey, Pennyslyvania, United States. It is edited by Rocci Luppicini who is a replacement professor in the Department of Communication at the University of Ottawa in Canada. The editor has published in a number of areas such as virtual learning communities and practice, research methodology on online instruction, issues in higher education, instructional design, design research, and online learning communities in education. Total of thirty-two authors contributed to the sections of the book. Authors vary from doctoral students to professors but almost all of them are experienced in the field of educational technology, instructional design, and communication technologies.

The Handbook presents a collection of papers to inform students, instructors, researchers, and managers about current instructional design practices and research. The book is divided into four main sections based on conversational frameworks for instruction: Section 1 explains Conceptual Frameworks in Conversation Design; Section 2 relates Conversation and Design for Instructional Applications; Section 3 exemplifies Instructional Applications in Conversation Design; and Section 4 elaborates on Emerging Trends in Conversation Design.

The first part of the Handbook examines conversation theory and conversation design. First chapter introduces theoretical and historical groundwork for understanding conversational design. After summarizing last 40 years of conversational design background in historical and theoretical context, the chapter concludes practical applications in conversation design for the $21^{\text {st }}$ century. In chapter 2 , the author explains the development of conversation theory and its applications chronologically while working with Gordon Pask at System Research Corporation between 1968 and 1978. Chapter 3 examines Pask's two main frameworks from conversation theory: A structure for the architecture of conversations and a schema for modeling the evolution of conversations. According to the author, these can be used to mirror how design happens. Chapter 4 discusses the development of Pask's conversation theory and its limitations with the human centrality of conversational learning. The chapter 5 explores the relationship between the activity of design and conversation - particularly as developed in Gordon Pask's Conversation theory. The chapter also analyses key concepts of conversation theory including interaction, learning, knowledge and the modeling facility. The last chapter of the Section one, Chapter 6 adapts Pask's conversation theory to the domain of education especially learning in online environments and communities of learning.

The second part of the Handbook discusses theoretical perspectives and applied cases in conversation design. Chapter 7 introduces a model for coding electronic discussion in the electronic discussion age. The chapter examines discussion possibilities of the model. In chapter 8, the contributor examines Pask's conversation theory for designing blended courses 
using a collaborative inquiry approach for teaching and learning in a campus-based university. Chapter 9 focuses on the design of conversations in online education. The aim of the chapter is explained as offering theoretical and methodological approaches to the design of learning conversations as a mode of learning and constructing knowledge. Chapter 10 defines instructional conversations and presents taxonomy of five types, ranging from dialectic conversations to reflective conversations. The chapter ends with a set of suggestions for improving professional practice particularly for instructors. In chapter 11 , the author reviews existing work on online bulletin board dialogues (OBBDs) and explores strategies and principles of conversation design based on media richness theory. Chapter 12 presents a model for the design of a conversation space to support knowledge-building based on Nonaka's work. The broader message of the chapter is that designers need to expand their frame of thinking about online learning to include not only the virtual space but also the local spaces which learners inhabit to create useful and engaging learning experiences.

The third part of the Handbook presents a series of chapters on current developments and methodological perspectives emerging from key instructional applications of conversation design. Chapter 13 contributes a grounded conversation design approach for online learning environments. This approach is applied to online learning contexts to leverage conversation quality and learning. The chapter suggests how basic grounded conversation techniques can be applied in a variety of learning environments to study conversation and develop conversation theory within the context of online learning. Chapter 14 reviews the literature of conversation in online environments, introduces the technologies that facilitate online conversation, and provides practical suggestions and strategies for planning online courses. In chapter 15 , the contributors introduce storytelling techniques that are told by both instructor and the learners to make an effective tool for promoting conversation among students. Chapter 16 introduces conversation theory as a means of creating an active learning environment in an elementary mathematics methods course. The authors' hope in this chapter is that an understanding of conversation theory as applied to teaching mathematics will help instructors and instructional designers. Chapter 17 shows how the interpersonal action-learning cycle (IALC) can be used to invite thinking alternative comprehension in conversation. The chapter presents how interpersonal learning takes place within the interpersonal action-learning cycle. It also shows that conscious use of the interpersonal action-learning cycle (IALC) offers a solution. The purpose of the chapter 18 is to explore design as it is live out in the communication processes amongst stakeholders involved in the context of school chance and design of new learning environments.

The fourth part of the Handbook focuses upon current trends and addresses a number of emerging areas in conversation design for the twenty-first century. Chapter 19 presents core components of self-organized-learning (SOL) model created by Sheila Harri-Augstein and Laurie Thomas. The authors draw on a variety of knowledge bases (including Paskian conversation theory) in describing their own approach to modeling personal meaning for effective action. Chapter 20 focuses on the design and evaluation of embodied conversational agents for educational and advisory software. The chapter provides guidelines and approved methods for the development of animated pedagogical agents including the extraction of multimodal tutorial strategies from human-human teaching dialogues as well as the simulation and evaluation of such strategies in computer-mediated learning environments. In chapter 21, the origins and state of the art of spoken multimodal instruction are described. This chapter examines the development of multimodal instructional systems chronologically. Chapter 22 focuses on mobile technology and its practical applications in instructional conversation. Chapter 23 introduces the concepts, principles, and application of dialogue mapping. The 
author explores the impact of dialogue mapping on collaborative learning along with factors influencing the effectiveness of group meetings in problem-based learning. Chapter 24 describes how social politeness is relevant to computer system design. The authors provide valuable advice to new designers and researchers concerning the importance of understanding social aspects of the Internet software.

In conclusion, this Handbook generally highlights the central role of instructional design and conversation within the context of instructional applications. The book is well-written and relatively well-organized. It adds significantly to the literature that addresses global perspectives on instructional design and theory of conversation. Cases represent different examples from diverse areas. Therefore, the Handbook is particularly useful for instructional designers, researchers, teachers, educational technology professionals, and policy makers who work for disseminating worthy instructional design applications.

Correspondence: Murat Ataizi, Associate Professor, Faculty of Communication Sciences, Anadolu University, Yunus Emre Campus, Eskisehir, Turkey 